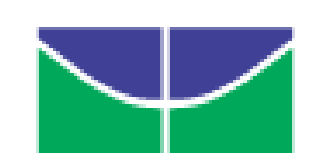

UNIVERSIDADE DE BRASÍLIA

Centro de Excelência em Turismo

Curso de Especialização em Turismo: Cultura e Lazer

\title{
TURISMO SUSTENTÁVEL E LAZER EM CALDAS NOVAS
}

Taíne Rezende Dias

Brasília, DF, junho de 2005. 


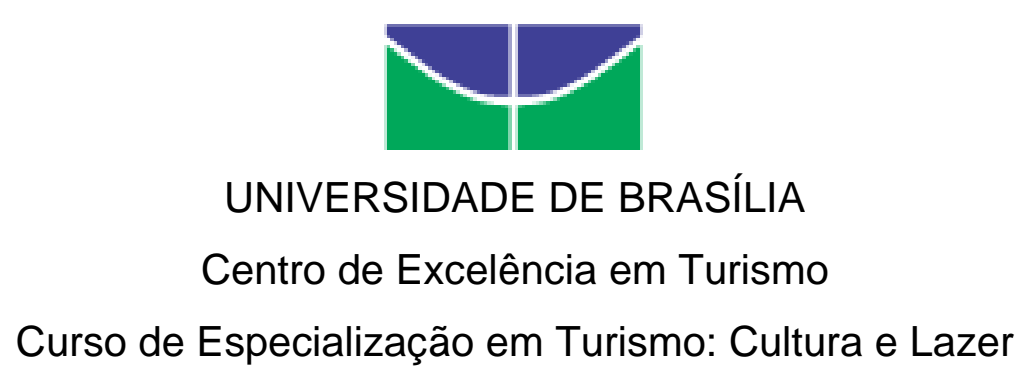

TURISMO SUSTENTÁVEL E LAZER EM CALDAS NOVAS

Aluna: Taíne Rezende Dias

Orientadora: Profa. Dra. Dulce Suassuna

\begin{abstract}
Monografia apresentada ao Centro de Excelência em Turismo da Universidade de Brasília como parte dos requisitos para a obtenção do título de especialista em Turismo: Cultura e Lazer.
\end{abstract}

Brasília, DF, junho de 2005. 


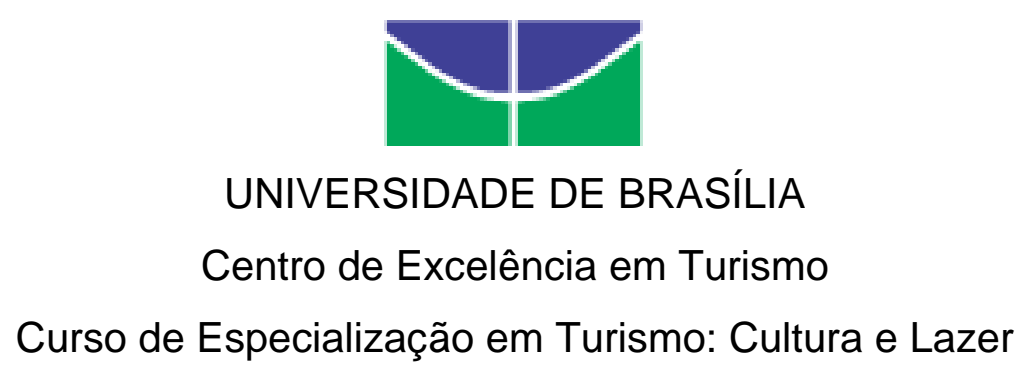

TURISMO SUSTENTÁVEL E LAZER EM CALDAS NOVAS

Taíne Rezende Dias

Banca Examinadora

Profa. Dra. Dulce Suassuna

Orientadora

Prof. Ms. Marcelo de Brito

Examinador

Brasília, DF, junho de 2005. 


\section{DEDICATÓRIA}

Aos meus queridos pais, o sincero agradecimento pela possibilidade de realizar mais um sonho, e principalmente por serem exemplos de vida, possibilitando e fomentando minhas conquistas.

Ao meu namorado pelo amor e compreensão.

A Deus agradeço a vida. 


\section{AGRADECIMENTO}

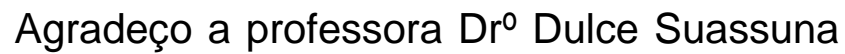
por ter me orientado de forma tão eficiente e carinhosa e me proporcionado às ferramentas necessárias à elaboração de minha monografia.

A você Dra Dulce o meu muito obrigada pelo empenho, paciência e dedicação na realização de mais um trabalho. 


\section{SUMÁRIO}

RESUMO

07

ABSTRACT

08

INTRODUÇÃO

09

CAPÍTULO I - PENSANDO O TURISMO SUSTENTÁVEL EM CALDAS NOVAS..

17

CAPÍTULO II - O LAZER EM CALDAS NOVAS.

25

2.1 - O Lazer enquanto cenário.

26

2.2 - Problematizando o lazer em Caldas Novas.

29

CONSIDERAÇÕES FINAIS

37

BIBLIOGRAFIA

39

ANEXO.

41 


\section{RESUMO}

O presente trabalho tem por objetivo analisar os espaços e equipamentos de lazer em Caldas Novas, como forma de propiciar um olhar crítico sobre a relação construída entre lazer e turismo naquele contexto. Pretende, especificamente, verificar em que medida é possível inserir como parte do roteiro turístico de Caldas Novas uma outra concepção do lazer, que propicie a diversificação dos espaços e equipamentos de lazer predominantes na cidade. A pesquisa utilizou como técnicas a entrevista, a aplicação de questionário e a observação. Tais técnicas serviram para traçar o perfil do turista de Caldas Novas, visando a aumentar o número de permanência dos mesmos na cidade. Além disso, por meio delas também foi possível identificar e registrar os espaços e equipamentos de lazer ofertados pela cidade. Como opções para a construção de um roteiro alternativo propõe-se a visitação ao Lago de Corumbá e ao Parque Estadual da Serra de Caldas Novas. Nesses lugares os turistas poderão praticar, respectivamente, o turismo náutico e o ecoturismo. Finalmente, recomenda-se um programa de turismo sustentável com a participação da população local no planejamento da atividade turística.

Palavras-chaves: lazer, turismo sustentável e Caldas Novas. 


\begin{abstract}
The present work has an objective to analize the spaces and ammusement equipaments in Caldas Novas, as a way to provide a critic look about the relation built between leisure and toursm in that context. Intending, to specifiy in what measure is possible to insert as a part of the touristic itinerary from Caldas Novas as another conception of leisure, that provides different spaces and equipaments of leisure that are in the city.

The research worked with tedxniques: the interview forms application and observation. Such techniques were used to have the tourist body way from Caldas Novas, viewing the rise of permanence numbers from the city. Besides that, from those was also possible to identify and register the spaces and leisure equipaments offered by the city. As options to an alternative itinerary construction set "Lago do Corumbá" visitation and to the state Park from "Serra de Caldas Novas". In these places the tourists will have a place to practice, respectifuly, the nautic tourism and the echotoristim. Finally, recommend a program about tourism with people participation in the tourist activity.
\end{abstract}

Key words: leisure, tourism supportable and Caldas Novas. 


\section{INTRODUÇÃO}

Caldas Novas está situada no estado de Goiás, a aproximadamente 170 quilômetros de Goiânia, capital do estado. Sua população atual é de 52.771 habitantes, de acordo com dados do último Censo (IBGE, 2001). Possui

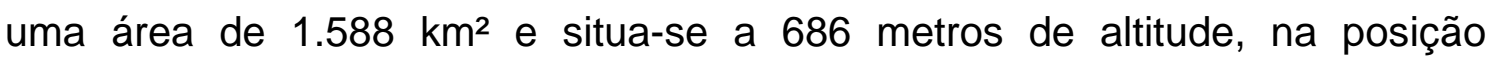
geográfica localizada no paralelo $17^{\circ} 44^{\prime} 37^{\prime \prime}$ Sul, em interseção com o meridiano 48 37' 33" Oeste (Fonte: Secretaria de Turismo e Cultura de Caldas Novas, 2002).

O município de Caldas Novas faz limite com os seguintes municípios: ao Norte; Santa Cruz de Goiás (69 km), Pires do Rio (80 km) e Piracanjuba (83 km); ao Sul; Marzagão (34km) e Corumbaíba (50km); a leste; Ipameri $(60 \mathrm{~km})$ e a Oeste; Rio Quente $(20 \mathrm{~km})$ e Morrinhos (54 km). À distância entre Caldas Novas e importantes centros urbanos não pode ser considerada muito grande, considerando as dimensões territoriais do nosso país, como é apresentada na tabela abaixo:

Tabela 1 - Cidades e distâncias em km de Caldas Novas:

\begin{tabular}{|c|c|}
\hline CIDADES & DISTÂNCIA (KM) \\
\hline Goiânia & 170 \\
\hline Uberlândia & 198 \\
\hline Brasília & 290 \\
\hline Uberaba & 351 \\
\hline São José do Rio Preto & 471 \\
\hline Araxá & 613 \\
\hline Belo Horizonte & 667 \\
\hline São Paulo & 781 \\
\hline Rio de Janeiro & 1034 \\
\hline
\end{tabular}

Fonte: IBGE (2002) e Prefeitura Municipal de Caldas Novas(2002).

Além disso, considerando o aspecto da distância também se deve observar que Caldas Novas possui um aeroporto, que recebe vôos regulares e fretados de Brasília, São Paulo e de outros estados da federação. 
Como potencialidade turística, Caldas Novas apresenta as águas termais, sendo uma estância hidromineral, com fontes de águas medicinais a 37/50 C (Pellegrini Filho, 1997). Tem notável destaque no turismo nacional por ser reconhecida como a maior estância hidrotermal do mundo, por isso muitos turistas vêm a esta cidade com o intuito de desfrutar dos atrativos turísticos, espaços e equipamentos de lazer. Com esse desempenho, Caldas Novas é o $9^{\circ}$ município mais competitivo no estado, ocupando, ainda, o $6^{\circ}$ lugar em dinamismo, $8^{\circ} \mathrm{em}$ qualidade de vida e $11^{\circ} \mathrm{em}$ riqueza econômica. No segmento do turismo, a Agência Goiana de Turismo - Agetur classifica Caldas Novas como Município Diamante, a categoria mais alta de classificação de nível de desenvolvimento turístico, o que habilita a cidade a obter da agência apoio nas ações de promoção e divulgação de eventos.

Contudo, dois aspectos devem ser levados em consideração acerca do papel do turismo e do crescimento econômico em Caldas Novas: 1) o que representa o turismo, como atividade econômica, para a cidade? 2) Em que medida a população local tem se beneficiado das políticas para o setor do turismo na cidade? Tais questões são importantes em decorrência da noção que se pretende trabalhar como eixo norteador do trabalho, qual seja, o turismo sustentável. Para tratar-se de turismo sustentável deve-se considerar como aspecto prioritário à população local, isto é, a cidade é principalmente do seu morador ou habitante, sendo assim ele deve ser parte essencial da definição das políticas de turismo e lazer.

Caldas Novas foi descoberta, de acordo com fontes históricas e relatos contados por antigos moradores, em 1722, por Bartolomeu Bueno Filho, filho do "Anhanguera", ao se dar conta da existência das fontes principais do Rio Quente que brotavam no sopé da Serra de Caldas (atualmente município do Rio Quente). O encantamento pelas águas quentes mudou os rumos e objetivos dos primeiros exploradores que aqui chegaram no final do século XVIII. (citado por Albuquerque, 1996: 33).

Cinqüenta e cinco anos mais tarde, em 1777, chega o bandeirante Martinho Coelho de Siqueira a essa região, conhecida como Caldas de Santa 
Cruz, devido à proximidade das fontes termais com o arraial de Santa Cruz. Segundo os relatos da época, os cães de Martinho Coelho estavam caçando um veado, quando caíram nas fontes termais e se escaldaram, fazendo grande barulho e chamando a atenção de seu dono. (Albuquerque, 1996: 44).

Martinho Coelho de Siqueira viu nas águas quentes um potencial de aproveitamento econômico e resolveu se fixar na região. Onde construiu a sede de sua fazenda, onde hoje se situa o Serviço Social do Comercio - SESC e é considerada a primeira casa de Caldas Novas. Nascia aí a primeira história das águas quentes de Caldas Novas, história de um arraial que virou cidade. E hoje é a capital das águas quentes (Albuquerque, 1996: 51).

Atualmente Caldas Novas conta com vinte e quatro hotéis com parque aquático, dezoito hotéis sem parque aquático e vinte e cinco pousadas. E a cidade recebeu os seguintes prêmios: •ll Troféu Imprensa 10/12/2003, Oferecido pelo Jornal CNN. • Prêmio de Ecoturismo 24 de Novembro de 2003. 25/10/2003 em São Paulo.“Menção Honrosa Especial ao”. "Destino Turístico de Caldas Novas."

Diploma de Honra ao Mérito em agradecimento e reconhecimento pelos serviços prestados ao desenvolvimento do turismo de Caldas Novas.

Oferecida pela ACICAN Associação Comercial e Industrial de Caldas Novas 13 de Agosto de 2004. (Fonte: Secretaria de Turismo e Cultura de Caldas Novas - 2004).

Caldas Novas recebe anualmente cerca de 1,5 milhão de turistas que visitam a cidade pelo fato de a mesma ser privilegiada pelas águas termais e também pelo seu ambiente bucólico. A cidade conta com uma completa infraestrutura de hotelaria, bares, restaurantes e camping. Atualmente a cidade possui a maior rede de hotéis de lazer do interior brasileiro: são 42 hotéis e 25 pousadas oferecendo milhares de leitos, moldada para atender os turistas com eficiência e bons serviços de hotelaria. Há também na cidade outros tipos de hospedagem como podemos conferir na tabela abaixo. 
Tabela 2 - Relação hospedagem por temporada

\begin{tabular}{|r|c|c|}
\hline LOCAL HOSPEDAGEM & BAIXA (MAIO/02) & ALTA (JUL/02) \\
\hline Hotel/Pousada & $67,61 \%$ & $51,25 \%$ \\
\hline Casa de amigos/parentes & $10,80 \%$ & $16,61 \%$ \\
\hline Casa de veraneio própria & $10,80 \%$ & $12,86 \%$ \\
\hline Casa alugada & $8,92 \%$ & $2,14 \%$ \\
\hline Camping & $1,17 \%$ & \\
\hline
\end{tabular}

Fonte: Secretaria de Turismo e Cultura de Caldas Novas (2002).

Por meio dos dados, percebe-se que os turistas que visitam Caldas Novas se hospedam, prioritariamente, nos hotéis e pousadas, contudo devese perceber que as casas próprias de veraneio representam um percentual importante de ser considerado, em especial pelo incremento que se tem no setor da construção civil na cidade, com publicidade e divulgação em outros centros urbanos, como é o caso de Brasília. Enquanto, as agências de marketing e propaganda costumam divulgar Caldas Novas como sendo "um verdadeiro oásis de atrações no interior do Brasil".

Mas, é fato que além do que a publicidade divulga como sendo o mais importante roteiro da cidade de Caldas Novas, outros atrativos turísticos, como por exemplo: o lazer nas trilhas e o banho de água fria nas cachoeiras do Parque Estadual da Serra de Caldas devem ser destacados. O lazer nas trilhas, que pode ser considerado como turismo de aventura, na modalidade de caminhadas esportivas, por exemplo, pode consistir em importante aspecto para incrementar o setor do turismo. Ribeiro e Barros (1997) afirmam que essa modalidade de turismo tem apresentado contínuo crescimento e defendem a existência de um turismo ecológico que se subdivide em quatro classificações, destacando entre elas, o turismo tipo aventura desportiva de grupo, no qual são praticadas atividades como hiking, trekking, canoagem, alpinismo, espeleologia, que, segundo eles, "inclui modalidades alternativas de baixo investimento de capital fixo, mas de alto retorno; apoiado em ideologias ambientalistas e/ou místico-religiosas" (Ribeiro e Barros, 1997: 30). Neste sentido, é importante 
observar que o turismo de aventura em Caldas Novas tem potencial, posto que, além de a cidade possuir infra-estrutura, como já foi destacado, os lugares em que poderiam se realizar caminhadas ou passeios ecológicos se situam a 6 e 8 quilômetros do centro.

Além disso, existem outros atrativos que podem contribuir no redimensionamento do turismo no local, é o caso do lazer náutico. Caldas Novas possui um lago cuja área é de $65 \mathrm{Km}^{2}$ e pode atingir uma altura máxima de 595 metros, em relação ao nível do mar. Seu perímetro é marcado pela sinuosidade, chegando a atingir mais de 100 quilômetros de extensão. Chamado de Lago de Corumbá, que pode ser utilizado para banhos (de água fria), pesca, passeios de jet ski e/ou lanchas. Estes espaços de lazer têm sua importância para o roteiro turístico de Caldas Novas por propiciarem diversificação, conseguindo-se por meio deles a fuga dos roteiros tradicionais. Além disso, pode-se destacar o aspecto cênico, pois se tratam de espaços de grande beleza natural. A apropriação destes espaços como atrativos turísticos, pode engendrar um tipo de turismo diferenciado, caracterizado como turismo ecológico.

Recuperando a idéia de que o turismo ecológico está relacionado com a busca pelo conhecimento e fruição da natureza, Ceballos-Lascurain (1990) assim define turismo ecológico:

“(...) turismo que consiste em viajar para áreas naturais não degradadas ou não poluídas, com o objetivo específico de estudar, admirar e fruir a paisagem e suas plantas e animais, tanto quanto manifestações culturais (do passado e do presente) encontradas nessas áreas. Nesses termos, o turismo orientado para a natureza implica uma colocação científica, estética ou filosófica para cientistas, artistas ou filósofos profissionais. O ponto principal é que a pessoa que pratica ecoturismo tem a oportunidade de mergulhar na natureza de uma maneira normalmente não possível no meio ambiente urbano" (citado por Pellegrini Filho, 1997: 138). 
A partir da citação percebe-se que o turismo ecológico tem como significado um maior contato do homem com a natureza, mas essa busca do contato se assenta na necessidade de perceber a natureza como uma paisagem, algo belo, mas ao mesmo tempo distante. Assim, pode-se participar de um safári na África, sem perder de vista a sensação de segurança de estar em um carro blindado, em que se pode escapar a qualquer momento do perigo da selva, sugerindo-se que o risco no turismo ecológico está sob controle. Este caso em específico pode ser um tipo de turismo caracterizado por Ribeiro e Barros (1997) como "turismo tipo Cancun". Este tipo de modalidade turística apresenta: "uma complexa infra-estrutura de transportes, comunicação e serviços na região visitada, 'região-alvo', e em diversos pontos de saída, 'de captação', dispersos no mundo; consiste em empreendimentos de capitalismo transnacional apoiados por uma retórica de respeito ao meio ambiente e as culturas locais" Ribeiro e Barros (1997: 29).

O "turismo tipo Cancun" tem aspectos importantes de serem considerados, quais sejam: relação capitalismo transnacional e o respeito ao meio ambiente e à cultura local. Tais aspectos precisam ficar claros, pois parece haver um contra-senso nesta relação, pois como conciliar os interesses do capitalismo internacional com questões locais ou localismo e até mesmo com o meio ambiente. Isto porque o capitalismo transnacional sempre se pautou na necessidade de produzir em larga escala, sem se preocupar com o impacto causado ao meio ambiente e de uma maneira global, cuja principal implicação é a desconsideração do localismo. Vê-se, portanto, que na definição do "turismo tipo Cancun" uma relação ambivalente e dicotômica posta entre os interesses capitalísticos e os aspectos locais e de sustentabilidade ambiental.

A possibilidade de inserção de outro tipo de turismo em Caldas Novas tem relação direta com o fato de que o perfil do turista que visita Caldas Novas sofreu alterações significativas nos últimos anos, tanto do ponto de vista sócio-econômico, quanto de aspectos como faixa-etária, sexo e expectativas ao buscar Caldas Novas como roteiro de sua viagem. 
A mudança do perfil do turista que visita Caldas Novas está relacionada com um quadro mais amplo, como observam Ribeiro e Barros (1997). Neste âmbito, deve-se destacar alguns elementos importantes, considerando o período de 1980-2000. Através de um levantamento realizado pela Secretaria de Turismo e Cultura em 2003, verificou-se que o turismo em Caldas Novas, há dez anos recebia cerca de cinco mil turistas por ano e que em 2003 o número de visitantes passou para 1,5 milhão anualmente. Com isso a rede hoteleira cresceu $15,6 \%$ nos últimos cinco anos, tornando-se a principal atividade econômica da cidade: 1) o boom de desenvolvimento econômico, 2) crescimento populacional; em 1980 o número de habitantes era de aproximadamente 9.800 e no ano de 2000 esse número passou para 49.642 habitantes.

Assim, diante das modificações das condições internas de Caldas Novas tem-se o redimensionamento do perfil do turista que visita a cidade, bem como, das expectativas desses turistas em relação aos espaços e equipamentos de lazer. Um bom exemplo para se pensar essa mudança é o caso do perfil do turista do início do século $X X$, quando Caldas Novas recebia pessoas cujo intuito era o de buscar a cura em suas águas termais, ou seja, as pessoas procuravam a cidade que até então era conhecida apenas pelas águas medicinais para se curarem de alguma enfermidade. Atualmente, o perfil do visitante de Caldas Novas está relacionado com a necessidade de busca de lazer, diversão e, de certa forma, aventura, como fuga do cotidiano.

Desta forma, diante do contexto que se configura no setor do turismo e, em especial, as formas que o turismo vem sendo construído em Caldas Novas, apresenta-se como problema de pesquisa o seguinte conjunto de questões: o turismo presente em Caldas Novas tem bases sustentáveis? Como se dá à relação entre os espaços e equipamentos de lazer em Caldas Novas com o turismo sustentável? Em que medida a busca do turismo sustentável está relacionada com um "novo" perfil de turista que visita Caldas Novas, que busca lazer, diversão e aventura na construção de sua "viagem"? 
Diante das questões colocadas apresentam-se como objetivos os seguintes:

Analisar o turismo em Caldas Novas em relação a
sustentabilidade; equipamentos de lazer em Caldas Novas com o turismo sustentável;

$>\quad$ Entender o significado do turismo sustentável por meio da redefinição do perfil do turista que visita Caldas Novas.

A pesquisa, com abordagem qualitativa foi realizada em Caldas Novas no período de janeiro de 2005. Teve como delineamento o levantamento, isto é, consistiu numa pesquisa descritiva, em que se utilizou como técnica de coleta de dados o questionário, que foi aplicado aos turistas. As perguntas apresentadas no questionário eram fechadas e abertas correspondendo ao número de onze questões. Além desses dados, foram obtidos juntamente à Prefeitura Municipal de Caldas Novas e ao Instituto Brasileiro de Geografia e Estatística - IBGE informações relativas ao nível sócio-econômico da cidade, da população, as atividades econômicas da região e outros dados importantes para a contextualização de Caldas Novas como lócus do estudo. A análise dos dados ocorreu com base na técnica da análise de conteúdo, em que os dois elementos centrais analisados foram o turismo sustentável, tratado no capítulo 1 do trabalho e o lazer, analisado no capítulo 2. O total de questionários aplicados foi de 30 e seu roteiro encontra-se em anexo a este trabalho. 


\section{CAPÍTULO I \\ PENSANDO O TURISMO SUSTENTÁVEL EM CALDAS NOVAS}

A noção de turismo sustentável torna-se recorrente a partir da discussão sobre desenvolvimento sustentável ou sustentabilidade. O desenvolvimento sustentável recebeu impulso no início da década de 70, com a Conferência de Estocolmo, conhecida como Eco-72, e cujos princípios norteavam a busca de desenvolvimento e crescimento econômico das nações ancorada no equilíbrio ambiental e social (Suassuna, 2001). Contudo, embora tenha servido como alerta para os países desenvolvidos, a Eco-72 teve pouco impacto na definição das políticas nos países subdesenvolvidos, inserindo-se neste contexto o Brasil, posto que, naquela oportunidade o Estado brasileiro apresentava como política o crescimento econômico, com investimento no setor industrial e a questão da sustentabilidade ambiental não se era considerada importante (Suassuna, 2001).

Na década de 90, com a Rio-92, os países conseguem ratificar alguns importantes aspectos já discutidos na Eco-72 e constroem uma agenda, conhecida como Agenda 21, tendo como objetivo estabelecer pautas e metas a serem alcançadas por países desenvolvidos, em desenvolvimento e subdesenvolvidos com a finalidade de assegurar a sustentabilidade em cinco dimensões: social, econômica, espacial, cultural e ecológica (Sachs, 1993). É neste contexto que emerge a discussão sobre turismo sustentável, isto é, como aliar a atividade turística às dimensões de sustentabilidade? Tal preocupação fez surgir uma noção interessante que é a de ecoturismo ou turismo ecológico, que tem como pano de fundo uma visão conservacionista sobre a natureza, mas ao mesmo tempo enxerga o turismo como atividade econômica importante para gerar renda para comunidades locais. Conforme, Pellegrini Filho "Nos anos 80, o ecoturismo tomou impulso, tornando-se muito mais freqüente as viagens de aficionados do acampamento" (1997: 31), mas apesar deste impulso, o ecoturismo assumia uma face incipiente e não se 
ancorava nas dimensões de sustentabilidade apresentadas por Ignacy Sachs (1993).

Diante do contexto que se coloca a partir das décadas de 80 e 90 e enxergando o turismo sustentável como um processo fundamental, é importante inseri-lo na política do turismo de Caldas Novas para orientação de uso dos recursos naturais, da tecnologia, de investimentos, das instituições e das leis, bem como a adoção de novos valores nos quais o respeito à eqüidade, à justiça e à vida prevaleçam, como preconiza a concepção de desenvolvimento sustentável propagada na atualidade. O turismo sustentável traz ainda relevante contribuição ao demonstrar as implicações planetárias da problemática ambiental, o que coloca a necessidade de transformar a avaliação da sustentabilidade em prioridade na política de Caldas Novas.

Sintetizando, na sua essência, o conceito de turismo sustentável promove:

> A ampliação da visão de desenvolvimento: quando o define como mais do que o crescimento econômico.

A permanência do desenvolvimento: quando o define a preocupação com as futuras gerações.

$>\quad$ Um processo de mudança para o desenvolvimento: quando indica a necessidade de reorientação de uso dos recursos naturais, da tecnologia, dos investimentos, das leis e das instituições, e a adoção de novos valores pela sociedade.

Segundo a Organização Mundial do Turismo (OMT) a definição de Turismo Sustentável é:

"Aquele ecologicamente suportável em longo prazo, economicamente viável, assim como ética e socialmente eqüitativo para as comunidades locais. Exige integração ao meio ambiente natural, cultural e humano, respeitando a frágil balança que caracteriza 
muitas destinações turísticas, em particular pequenas ilhas e áreas ambientalmente sensíveis" (2003: 13)

Podemos perceber que o envolvimento do turismo com a questão da sustentabilidade vem se ampliando. Este fato fica evidente com o crescente número de publicações dedicadas ao tema e pelo aumento de interesses em preservar os patrimônios culturais e ambientais.

Por ser o turismo fortemente dependente da preservação do ambiente físico e patrimônio cultural, deve tratar estes recursos não apenas como sua matéria prima, mas encará-los sob a ótica de que constituem patrimônio comum da humanidade.

$\mathrm{Na}$ construção de uma nova ética para o turismo, apoiada no conceito de sustentabilidade, duas questões surgem como de especial relevância no momento atual. A primeira refere-se ao crescente interesse pelo turismo em regiões privilegiadas do ponto de vista do seu patrimônio natural e cultural, mas pobres, economicamente, o que requer cuidado especial no desenvolvimento da atividade turística, de modo a que ela não contribua para a exclusão social, degradação ambiental e descaracterização da cultura local. Outra questão é a urgência de reflexão sobre novos padrões de consumo e desenvolvimento do setor.

Segundo o autor, Swarbrooke (2000: 31), o turismo sustentável é uma questão de:

Manter as destinações existentes e impedir o início de sua deterioração;

$>\quad$ Administrar o desenvolvimento das novas destinações de tal forma que se possa assegurar sua futura sustentabilidade.

Também fica claro que turismo sustentável em todos os meios significa:

Meio ambientes sustentáveis;

Economias locais sustentáveis;

Comunidades locais sustentáveis. 
Enfim, os impactos da atividade turística podem ir muito além da degradação ambiental, por vezes irrecuperável; suas conseqüências poderão alcançar negativamente culturas e relações sociais, criando conflitos e inviabilizando o desenvolvimento das áreas atingidas pelo seu crescimento. $\mathrm{O}$ planejamento se impõe como um instrumento indispensável, dentro de uma abordagem sistêmica, como requerido pela noção de processo do conceito de sustentabilidade.

Trazendo a discussão para o cenário de Caldas Novas, deve-se registrar que o impulso do turismo na cidade, vindo, sobretudo, em decorrência de seus fatores climáticos e ambientais, em especial das águas termais, produziu o incremento econômico, mas também trouxe como conseqüência uma explosão demográfica, como mostram os dados do Instituto Brasileiro de Geografia e Estatística - IBGE. Segundo dados do Censo (IBGE, 2001), Caldas Novas apresenta uma população fixa de 52.771 habitantes e aproximadamente, 30 mil unidades residências construídas com uma média por unidade domiciliar de 3,53 habitantes. O desenvolvimento urbano de Caldas Novas chama a atenção pelos números expressivos, se comparado a outras cidades do interior do país, isto porque em 1996, a cidade cresceu a uma taxa de 20,8\% ao ano. Foi o segundo maior crescimento do Brasil e os dados da tabela ajudam a ilustrar o período em que ocorre este crescimento. Ver a seguir na Tabela abaixo:

Tabela 3 - População de Caldas Novas no período entre 1842 até 2001

\begin{tabular}{|c|c|}
\hline ANO & HABITANTES \\
\hline 1842 & 200 \\
\hline 1960 & 5.200 \\
\hline 1970 & 7.000 \\
\hline 1980 & 9.800 \\
\hline 1991 & 25.000 \\
\hline 2000 & 49.642 \\
\hline 2001 & 52.771 \\
\hline
\end{tabular}

Fonte: IBGE e Prefeitura Municipal de Caldas Novas (2002). 
O processo de crescimento de Caldas Novas tem, portanto, um duplo significado quando se situa a questão da sustentabilidade. De um lado, tem-se o aspecto positivo desse processo de desenvolvimento que é fato de Caldas Novas receber investimentos e capitais, por meio de fontes como a indústria da construção civil e, tendo como conseqüência uma urbanização acelerada de seus espaços no perímetro urbano, incluindo-se neste âmbito os espaços e equipamentos de lazer da cidade, tais como praças, parques aquáticos, clubes, entre outros. De outro lado, surge um problema que tem conseqüências em longo prazo, trata-se das questões ambientais, que envolvem a utilização da água e a urbanização acelerada da cidade, tendo-se com isso um lazer voltado para um público que quer ter conforto e segurança, como afirma Ribeiro e Barros (1997), um lazer tipo o turismo de Cancun.

Realizando um inventário do patrimônio natural do Brasil e, ao mesmo tempo, preocupado com o impacto causado pelo uso descontrolado dos recursos naturais e o impulso do turismo nessas localidades, Pellegrini Filho cita o caso de Caldas Novas como uma potencialidade realizada, assim diz o autor:

"A abundância de águas quentes é a atração central, bastante
procurada para lazer e também para tratamento de diversos
males físicos (neurastenia, artritismo, nefrites, nevralgias,
bronquites, raquitismo, asma etc). Em função desse bem
patrimonial natural, estabelecimentos hoteleiros dispõem de
recursos e serviços (piscinas, balneários, trenzinhos, bosques,
quadras de esportes) oferecendo motivações para maior
permanência no local e beneficiando o turismo de férias" (1997: 43).

Contudo, mesmo tendo-se em Caldas Novas o cenário de uma potencialidade turística realizada como mostra a avaliação de Pellegrini Filho (1997), tem-se alguns aspectos que devem ser destacados e que se remetem ao impacto causado pelo processo de urbanização acelerado que sofreu a cidade e também pelo uso dos recursos naturais disponíveis. Estes aspectos 
se apresentam como preocupação por se remeterem a conseqüências que levam a uma desigualdade na relação entre usufruto dos recursos naturais e crescimento urbano. Com isso não se pretende proibir o uso e aproveitamento dos recursos naturais e nem coibir o crescimento populacional, por exemplo, mas buscar meios em que o estabelecimento da relação apontada como desigual recebe do poder público uma apreciação cuidadosa no encaminhamento das políticas públicas para os setores do turismo e lazer. Nesse sentido, é válido questionar em que medida as políticas públicas em Caldas Novas direcionadas para o setor do turismo estão sendo implantadas e implementadas visando à concepção de sustentabilidade, apresentada anteriormente por meio da contribuição de Sachs (1993). Pelo que se percebeu no trabalho de campo, há um contínuo investimento do setor privado, em especial da indústria da construção civil, em construir prédios, urbanizar a cidade, concentrando no centro prédios luxuosos de condomínio para a classe média alta, que como observa Pellegrini Filho (1997) muitas vezes são utilizados para as férias no local.

Conforme a pesquisa realizada em janeiro de 2005, pode-se constatar que $54 \%$ dos turistas que vão a Caldas Novas tomaram conhecimento da cidade através de parentes, 30\% conheceram depois que alguns amigos falaram da beleza da cidade e apenas 16\% tiveram conhecimento por meio de uma agência de turismo.

Pelo resultado da pesquisa constatou-se que a grande maioria dos turistas (cerca de 76\%) que visita Caldas Novas se sente motivada pelo fato de conhecer as águas termais. Quatorze por cento das pessoas que vão a Caldas Novas, vão pelo fato de terem familiares na cidade. E apenas $10 \%$ vão por causa dos shows que são realizados, principalmente nos feriados e/ou nas férias.

Perguntou-se aos entrevistados como eles organizaram a sua viagem a Caldas Novas, e obtivemos o seguinte resultado: apenas 1\% organizou pela internet, $13 \%$ foi através de uma agência de turismo, 17\% 
organizou sozinho e a maioria dos entrevistados organizou com os familiares, cerca de $47 \%$.

O perfil do turista que vem a Caldas Novas no período de férias ou mesmo na baixa estação é interessante, pois grande parte $(44,37 \%$ em baixa temporada e 34, 64\% em alta temporada) vem do interior do estado de Goiás e de Goiânia, sendo o Distrito Federal o segundo em termos de visita àquela cidade nos períodos de baixa e alta temporada, como demonstram os dados da Tabela 4 que segue:

Tabela 4 - Origem do turista que visita Caldas Novas.

\begin{tabular}{|c|c|c|}
\hline ORIGEM & BAIXA TEMP.(MAIO/02) & ALTA TEMP. (JUL/02) \\
\hline Goiânia e Interior & $44,37 \%$ & $34,64 \%$ \\
\hline Distrito Federal & $18,54 \%$ & $21,55 \%$ \\
\hline São Paulo & $16,67 \%$ & $18,04 \%$ \\
\hline Minas Gerais & $11,97 \%$ & $10,89 \%$ \\
\hline Outros & $8,45 \%$ & \\
\hline
\end{tabular}

Fonte: Secretaria de Turismo e Cultura de Caldas Novas (2002).

Diante desses dados, percebe-se que Caldas Novas passa a representar para a população que vive na região Centro-Oeste uma cidade que se torna roteiro de férias, como aconteceu com cidades litorâneas do Brasil durante as décadas de 70, 80 e 90. Conquanto, é importante salientar que no caso das praias que se tornaram casas de veraneio da população de classe média que vivia em centros urbanos, houve a expulsão da população local para locais menos privilegiados, em que não poderiam mais desfrutar da proximidade em relação ao uso das praias. Sobre este aspecto é importante mencionar a análise de Luchiari (1997: 67) ao afirmar que:

"Além da expropriação causada pela crescente especulação imobiliária e pela valorização turística da região, os caiçaras também foram desapropriados pela legislação do Parque Estadual da Serra do Mar, território interdito para as atividades 
agrícolas, de pesca nos rios, de extração (principalmente da caxeta, para o artesanato, ou de madeiras mais nobres, para a confecção de barcos) e de caça. Se, de um ponto de vista positivo, a legislação ambiental restringe a expansão urbana desenfreada, por outro lado, também restringe a utilização dos recursos naturais pelas populações tradicionais, criando um conflito evidente entre as leis de preservação ambiental e preservação do modo de vida caiçara".

Desta forma, no planejamento urbano é preciso dimensionar o espaço em que as populações locais ocuparam, bem como perceber o custo social para a população do crescimento acelerado de atividades econômicas importantes, como são a construção civil e o turismo, procurando situar o que as implicações dessas atividades no modo de vida e na possibilidade de usufruto por parte daqueles que são moradores da cidade. Assim, o exemplo citado por Luchiari (1997) contribui para se repensar a política de turismo em Caldas Novas e em outras cidades que passam por processos similares. 


\section{CAPÍTULO II \\ O LAZER EM CALDAS NOVAS}

Costuma-se definir o século XVIII como o século da Revolução Industrial, em virtude do aparecimento de uma série de invenções técnicas que modificam as condições de produção nos diversos setores industriais, bem como as relações entre empregados e empregadores.

O Marcellino acredita (1983: 14) que:

"A gestação do fenômeno lazer, como esfera própria e concreta, dá-se, paradoxalmente, a partir da Revolução Industrial, com os avanços tecnológicos que acentuam a divisão do trabalho e a alienação do homem do seu processo e do seu produto. O lazer é resultado dessa nova situação histórica - o progresso tecnológico, que permitiu maior produtividade com menos tempo de trabalho. Nesse aspecto, surge como resposta a reivindicações sociais pela distribuição do tempo liberado do trabalho, ainda que, num primeiro momento, essa partilha fosse encarada apenas como descanso, ou seja, recuperação da força de trabalho".

Dentre as mudanças introduzidas na sociedade pela Revolução Industrial, uma particularmente influenciou o turismo: a separação entre o tempo de trabalho e o tempo de lazer. Embora não tenha sido de imediato, a constituição das sociedades industriais acabou por levar uma delimitação das jornadas de trabalho, pois os trabalhadores começaram a sentir a necessidade de descansar e de ficar mais tempo com a família, e mais tarde esse tempo passaria a se chamar de tempo livre.

O tempo livre à disposição das pessoas foi um fator de importante influência na formação do novo estilo de vida dos trabalhadores, onde esse 
tempo de liberdade do trabalho utilizado para o lazer, passa a ser uma prioridade social. Uma ampla variedade de atividades começou a surgir nas últimas décadas para preencher o tempo livre das pessoas. $E$ o desenvolvimento dessas atividades de lazer tornaram-se imprescindíveis na formação deste novo padrão social surgido com as mudanças contemporâneas.

A necessidade de tal divisão constitui um dos fatores determinantes da rigorosa organização das atividades produtivas, modificando as relações interpessoais no trabalho, a configuração da vida familiar e o próprio valor atribuído ao lazer.

O estudo do lazer vem se especializando, quer em termos de faixas etárias, quer em conteúdos de atividades. Atualmente, já podemos contar com um bom número de títulos que analisam o lazer infantil ou o da terceira idade, bem como bibliografias específicas sobre o assunto. O lazer constitui um setor importante da vida social.

Enfim, o lazer faz parte da vida das pessoas, é uma necessidade que todos nós sentimos, por isso faze-se uma grande diferença na qualidade de vida das pessoas. Os indivíduos que usufruem o lazer sentem - se muito melhor e até mesmo bem mais dispostos para praticarem qualquer outra atividade, inclusive o trabalho.

\section{1 - O Lazer enquanto cenário}

O lazer na sociedade moderna tende a ser visto como o momento do tempo livre ou do tempo do não-trabalho, enfim, o momento das desobrigações. Esta mentalidade gera um paradoxo para o tema lazer, pois o apresenta como algo compensatório e funcional na sociedade capitalista.

Para Negrine "o lazer apresenta-se como um elemento central da cultura vivida por milhões de trabalhadores influenciando em vários setores da 
civilização. O lazer tornou-se uma realidade fundamental apresentando aspectos múltiplos" (2001: p.75).

Atualmente o lazer faz parte da cultura de muitos trabalhadores e neste aspecto a influência da mídia se faz notável (principalmente a televisão) que de forma indireta acaba influenciando no modo de pensar e agir das pessoas. Portanto, essa nova cultura vivida resulta de uma mudança na atitude valorativa das ações humanas, e o trabalho situa, na civilização pósindustrial, como um meio para que se possa usufruir as atividades de lazer.

Camargo apresenta uma análise interessante sobre o espaço ocupado pelo lazer no período da consolidação do trabalho industrial, de acordo com o autor:

"O trabalho industrial não pode ser permeado pelo entretenimento, pelo lúdico, como no campo, onde estas necessidades eram satisfeitas até mesmo no ritmo do próprio trabalho. A própria organização do espaço de trabalho inibe qualquer tentação de diversão e entretenimento. Enfim, as longas jornadas de trabalho no inicio da industrialização apenas deixava tempo para o sono. Isso significa que o lazer beneficiou-se basicamente da redução da jornada de trabalho" (2003: 87).

Desta forma, percebe-se que havia um conflito estabelecido entre 0 tempo de trabalho e o descanso, mas que o lazer não tinha importância no contexto daquele processo de industrialização. Porém, o lazer surge na sociedade capitalista, a mesma sociedade que não lhe permite acesso na sua construção. O surgimento do lazer no capitalismo se dá em decorrência das lutas trabalhistas, que passam a exigir que o trabalhador tenha direito a 8 horas de trabalho, 8 horas de descanso e 8 horas de lazer, fato que ocorre no movimento trabalhista francês no início do século $X X$, com a greve dos metroviários de Paris (Masagão, 1990). 
Contudo, a utilização crescente da palavra "lazer" por amplos setores da população não se restringe a construções ou espaços. Pelo contrário, constitui apenas um exemplo da variada gama de situações em que é empregada: faz parte de conversas informais; ocupa títulos de revistas e seções de jornais; dá nome a clubes e lojas de artigos especializados; enfim, está presente no cotidiano das pessoas em geral. Isso é significativo, sobretudo se estabelecer à comparação com o que ocorria em épocas recentes ".

Neste sentido podemos concluir que: o lazer cresce com a urbanização, tornando-se assim um elemento importante e fundamental para a sociedade moderna.

Contudo, o lazer não obstante tenha surgido como uma forma de direito social se tornou uma espécie de subterfúgio nas mãos dos empregadores. Assim, o lazer passa a assumir uma face compensatória na contemporaneidade, em especial, no caso brasileiro com o surgimento do sistema "3 S" (Sesc, Senai e Sesi). Por detrás desse sistema a relação entre produção e lazer se corporifica, assim, o lazer terá um papel funcional e consistirá em um conjunto de atividades dirigidas a um público determinado e com a finalidade exclusiva de entretenimento.

Segundo Krippendorf, (2001: 13)

"A sociedade humana, outrora tão sedentária, pôs-se em movimento. Hoje, uma mobilidade frenética tomou conta da maioria dos habitantes das nações industriais. Aproveita-se de todas as oportunidades para viajar e fugir do cotidiano com a maior freqüência possível. Curtas escapadas no decorrer da semana ou no fim de semana, longas viagens nas férias. Assim é que, ano após ano, fim de semana após fim de semana, milhões de seres humanos se comprimem em multidões, sem necessidade alguma e sem obrigação aparente, consumindo esse período que lhes é tão precioso". 
No tempo de lazer o homem tem a possibilidade de realizar atividades que atendam às suas carências físicas e psicológicas. Respeitando as diferenças individuais, as pessoas podem identificar nos lazeres formas de resgatar a própria liberdade comportamental, sua homeostase física e psicológica, atuando em função de seus próprios desejos e predisposições.

Com efeito, é importante destacar que Dumazedier (1980) distingue cinco categorias quanto ao conteúdo das atividades de lazer: os interesses físicos, os práticos ou manuais, os artísticos, os intelectuais e os sociais. A meu ver sua classificação é a mais adequada para a compreensão do objeto em estudo, pois situa, no campo especifico do lazer, as atividades que buscam o atendimento das necessidades do corpo - conferindo destaque especial às habilidades manuais, da mente, da sensibilidade $\mathrm{e}$ da sociabilidade. Acho que assim procura abranger todos os aspectos que caracterizam o homem, no seu processo de devir.

\section{2 - Problematizando o lazer em Caldas Novas}

O lazer tornou-se um tema recorrente nos estudos do turismo. No prefácio do livro organizado por Serrano e Bruhns (1997), Hogan destaca que, embora o turismo seja relegado a segundo plano pelas ciências sociais, hoje ele requer uma reflexão mais sistemática que devem estar relacionadas com os aspectos culturais, sociais, políticos, ambientais e econômicos, podendose acrescentar este último aspecto que não foi citado pelo prefaciador. Além disso, Hogan destaca que atualmente o papel do turismo conquista um espaço importante sobretudo pelo "maior ócio dos afortunados que têm emprego" (1997: 7), gerando uma conseqüente demanda para oportunidades de turismo. Por meio das observações do autor, consegue-se ter a dimensão da relação e das implicações entre o turismo e o lazer. Como discutido no capítulo anterior, o turismo apresenta-se muitas vezes sob uma face inconseqüente não se preocupado com o significado das suas atividades e tão pouco com a sustentabilidade da população local. Agora, deve-se tratar 
do lazer e o que ele representa em termos conceituais e de ordem prática, revestido sobre a concepção de atrativos turístico em Caldas Novas.

Em termos conceituais o lazer pode ser compreendido como:

"Um conjunto de ocupações as quais o individuo pode entregarse de livre vontade, seja pra repousar, seja para divertir-se, recrear-se e entreter-se, ou ainda para desenvolver sua informação ou formação desinteressada, sua participação social voluntária ou sua livre capacidade criadora após livrar-se ou desembaraçar-se das obrigações profissionais familiares e sociais" (Dumazedier, 1980: 18).

Neste conceito se sobressai o papel da livre vontade, ou seja, da liberdade que tem o sujeito em escolher o que ele pretende fazer com o seu tempo livre (tempo do não-trabalho). Contudo, embora do ponto de vista conceitual a noção apresentada por Dumazedier tenha importância, do ponto de vista prática, pretende-se questionar se ela efetivamente se verifica, considerando o caso do turismo em Caldas Novas.

Caldas Novas, como já foi dito no capítulo anterior, apresenta uma gama de oportunidades de entretenimento e diversão nos seus hotéis e clubes, viu-se que a programação apresentada por esses espaços é considerada pelos turistas como suficiente e também que os mesmos tiveram suas expectativas superadas. A esse respeito pretende-se apresentar os outros atrativos turísticos de Caldas Novas: o Lago de Corumbá e Parque Estadual da Serra de Caldas Novas - PESCAN.

\section{O Lago de Corumbá}

O lago da Hidrelétrica de Corumbá é alimentado pelos rios Pirapitinga, Piracanjuba, Peixe e São Bartolomeu. A hidrelétrica foi construída pela CELG em 1979. Em 1984, Furnas assumiu o empreendimento, terminado 
o processo de construção da barragem no ano de 1996. O processo de enchimento do reservatório foi concluído em janeiro de 1997.

O Lago de Corumbá ocupa uma área de $65 \mathrm{Km}^{2}$ e pode atingir uma altura máxima de 595 metros, em relação ao nível do mar. Seu perímetro é marcado pela sinuosidade, chegando a atingir mais de 100 quilômetros de extensão. A construção do Lago de Corumbá permitiu o aparecimento de uma série de alternativas para o turismo e para o desenvolvimento econômico.

O Lago de Corumbá está situado a oito quilômetros do centro de Caldas Novas. Com uma infraestrutura ainda bucólica, nas proximidades, existem restaurantes, marinas e lanchonetes.

No local, também se encontram disponíveis aluguéis de lanchas, jet ski e barcos. Com visitas a quatro cachoeiras e/ou passeio de barco com capacidade para 100 pessoas (Eco Nave). O passeio de barco no lago tem $2 \mathrm{~h}$ de duração. Para a realização desses passeios os grupos são formados na cidade.

\section{Parque Estadual da Serra de Caldas Novas - PESCAN}

Para quem ama a natureza é uma boa alternativa. Criado em 1970 para proteger o principal ponto de recarga do lençol termal da região de Caldas Novas, o parque está estruturado à visitação pública desde 1999. O PESCAN (Parque Estadual de Caldas Novas) situa-se a seis quilômetros do centro da cidade, a Serra tem $15 \mathrm{~km}$ de extensão por $9 \mathrm{~km}$ de largura, com altura máxima de 1043 metros em relação ao nível do mar de 460 metros em relação à cidade.

Além de ter uma bela vista da cidade, o alto do Parque Estadual da Serra de Caldas proporciona aventuras em trilhas. As trilhas dessa serra são leves, e qualquer um, ao lado do guia, pode subir pela mata. Há quatro trilhas 
para você escolher. A Trilha da Asa Delta é a de maior altitude, por isso, tem vistas incríveis.

Nas trilhas da Cascatinha, Córrego de Caldas e do Paredão há piscinas naturais e cachoeiras. A primeira é a de acesso mais fácil e a última, a mais longa.

O parque conta com guias para passeios ecológicos nas trilhas da Cascatinha (700 metros) e Paredão (1.500 metros). A trilha do Paredão classifica de grau médio de dificuldade, possui uma parada em mirante de onde se avista a cidade de Caldas Novas. Já a trilha da Cascatinha é considerada de grau leve. Em ambos, o turista poderá se deliciar com um banho de cachoeira e nadar em piscinas de água fria. Estes dois trechos perfazem $11 \mathrm{Km}$.

Para caminhar pela Serra o visitante paga uma taxa simbólica no valor de $\mathrm{R} \$$ : 5,00, já que o passeio só pode ser feito com guia. A sede da coordenação possui estrutura para a realização de eventos, trabalhos de pesquisa e estudos, com auditório, salas de exposição e outras aéreas.

Tendo em vista a pouca presença turística, registrada por meio da observação direta nos atrativos turísticos acima descritos, questionou-se aos turistas visitantes de Caldas Novas quais eram suas expectativas quanto à oferta de atrativos turísticos, ao que responderam: 13\% dos entrevistados esperavam encontrar lazer noturno para se divertirem, 20\% queria encontrar a cidade cheia de gente, $24 \%$ esperava por tranqüilidade para descasarem e $43 \%$ queriam mesmo conhecer as piscinas de águas quentes naturais.

O lazer está diretamente relacionado à análise dos objetivos mais gerais do comportamento humano o que se remete à teoria de Maslow,na qual todas as atividades do individuo parecem ser governadas por quatro objetivos gerais, separadamente ou por uma combinação deles: sobrevivência; segurança; satisfação; estimulação (Bacal; 2003). 
Esses quatros objetivos são fundamentais para que o individuo sinta vontade de praticar alguma atividade de lazer. Visto que a sobrevivência é essencial, assim como a segurança, mas também os demais objetivos são fundamentais, pois se não houver satisfação e estímulo o individuo não se sentirá interessado em praticar tais atividades. Com isso se percebe que o lazer no contexto da sociedade capitalista não se apresenta como algo emancipador, mas como um conjunto de atividades dirigidas. Por esta razão o turista considera suficiente o lazer ofertado para ele por seu hotel ou clube, não tendo a necessidade de conhecer outros atrativos e muito menos de efetivamente participar da vida da localidade que está conhecendo. Este aspecto deve ser recordado, pois como uma atividade humana, o turismo pode representar "uma via de inserção na realidade do outro, de grande potencial pacifista e integrador, que infelizmente, na maioria das vezes, termina por ser banalizada pela mercantilização" (Ribeiro e Barros, 1997: 40). Sendo assim, acredita-se que o lazer, expresso por meio de atividades alternativas, pode representar uma possibilidade de fuga do sentido de mercantilização presente nos atrativos apresentados pelo setor do turismo em Caldas Novas, em particular, pela rede hoteleira e clubes.

As atividades de lazer estão cada vez mais presentes na vida das pessoas, indistintamente, quando mais não fosse, pela simples difusão dos meios de comunicação de massa. No entanto, quando se tem em mente as possibilidades que o lazer oferece em termos de variedade de ocupações ou das funções que possa cumprir, ou seja, quando o critério deixa de ser quantitativo e se transforma em qualitativo, buscando-se detectar a apropriação do lazer enquanto atitudes ativas: diversão, repouso e criatividade.

Conforme resultado da pesquisa constata-se que a maioria dos turistas gosta mais dos clubes (63\%), 23\% já preferem o conforto que os hotéis oferecem, $17 \%$ disseram que gostam mais do Náutico e apenas 7\% votaram na Serra de Caldas. Este desenho permite que se repense no modelo de desenvolvimento de turismo apresentado, em especial, tendo em vista que os dados retratados por esta enquête se relacionam com o tipo turismo 
Cancun apresentado por Ribeiro e Barros (1997). O que atrai os turistas são os aspectos da infra-estrutura e dos serviços oferecidos. Contudo, a questão que se coloca neste âmbito é o que representa o impacto da geração de políticas do setor do turismo e lazer para o turismo tipo Cancun. Neste caso, não há um direcionamento das atividades voltado para a sustentabilidade e também há pouca ou nenhuma preocupação com as opiniões e demandas da população local, o que importa efetivamente é que o turista se sinta numa verdadeira ilha paradisíaca e possa desfrutar dos recursos naturais e de serviços oferecidos pela rede hoteleira. Isto quer dizer que o turismo tipo Cancun se torna uma retórica da sustentabilidade. Aliando-se a este fato o aspecto de que a maioria dos entrevistados (cerca de 70\%) já tinha indo a Caldas Novas antes e apenas 30\% iam pela primeira vez. E ao se perguntar aos mesmos se eles pensavam em voltar outras vezes e a resposta foi unânime, dizendo que sim.

Assim, concorda-se com o que afirmam Ribeiro e Barros (1997: 35) sobre a construção do sujeito e sua diferenciação social:

"Com a saturação das imagens pelos meios de comunicação de massa, que trazem uma circulação inusitada de ícones para consumo em grande escala, a experiência individual direta com o ambiente, a paisagem e os nativos - o being there dos antropólogos e dos turistas - passa a ser um valor dos mais apreciados para a afirmação do individualismo contemporâneo, já que, pretensamente, propicia um afastamento dos simulacros e das rotinas aos quais os indivíduos e suas redes sociais estão expostos no dia-a-dia".

Assim, mesmo que Caldas Novas seja parte de um roteiro turístico nacional, as suas potencialidades turísticas permitem ao visitante a sensação de estar gozando de um verdadeiro paraíso, em que todas as possibilidades são possíveis. Desde se aquecer em piscinas termais e naturais, até em assistir a espetáculos de artistas nacionais, em especial de apelo frenético, 
como é o caso do Axé Music e outros gêneros musicais que se apresentam em grandes hotéis da cidade.

Perguntou-se, também, quais eram as expectativas dos turistas sobre Caldas Novas, se elas haviam sido boa ou até mesmo superada em relação à oferta de atrativos turísticos: a maioria respondeu que a expectativa foi superada, o que equivale a $43 \%$ dos entrevistados, $37 \%$ respondeu que a expectativa foi boa e apenas $20 \%$ classificaram como regular o lazer em Caldas Novas. Com isso, percebe-se que o lazer em Caldas Novas atende ao perfil do turista que freqüenta o lugar, contudo, a questão da inserção de um outro roteiro pode ser um elemento que subsidie a redefinição da política de turismo da cidade, especialmente, em relação a sustentabilidade e à participação da população local na discussão da política. Embora, a expectativa do turista tenha sido superada em relação às atividades de lazer em Caldas Novas, deve-se mencionar que a maior parte dele $(67,61 \%$ em baixa temporada e 51, $25 \%$ em alta temporada) se instala em hotéis e deles não sai para conhecer os outros atrativos que a cidade oferece. Assim, o lazer que o turista indica como satisfatório diz respeito aos espaços e equipamentos ofertados pelo complexo hoteleiro em que ele se hospeda.

Procurou-se saber também, como os turistas classificam o lazer em Caldas Novas. Trinta e sete por cento acham excelente o lazer oferecido pela cidade, 33\% classificaram como bom e 30\% acreditam que o lazer na cidade precisa melhorar muito. Então, perguntou-se a essas mesmas pessoas o que elas achavam que precisava ser melhorado no lazer: $20 \%$ acham que a recreação dentro dos clubes precisa ser melhorada; $17 \%$ já querem que os preços dentro dos clubes sejam mais acessíveis; 23\% estão satisfeitos com o lazer da cidade, mas a maioria acha que precisa ter mais atrativos. Nesse sentido, deve-se observar duas questões: a primeira a relação estabelecida entre o lazer, o entretenimento e a recreação e a segunda do significado que o lazer deve ocupar no cotidiano das pessoas, a este respeito é importante considerar o que diz Marcellino: 
"O lazer não pode mais ser encarado como atividade de sobremesa ou moda passageira. Merece tratamento sério sobre suas possibilidades e riscos. Nesse sentido, [propõe] considera-lo não como simples fator de amenização ou alegria para a vida, mas como questão mesmo de sobrevivência humana, ou melhor, de sobrevivência do humano no homem (1983: 87)".

Entretanto, nem todos os autores têm a mesma idéia de que o lazer está totalmente "desligado" das atividades profissionais. Trigo, (1998: 52), afirma que:

\footnotetext{
"Atualmente nas sociedades contemporâneas, a utilização do tempo livre não obedece a modelos preestabelecidos para todos nem esta necessariamente separada da atividade profissional o cultural. 0 tempo livre pode ser utilizado para "fazer nada" ou para o ócio para o lazer individual ou coletivo, seja ele espontâneo ou programado; para atividades culturais, esportivas ou para o turismo. Muitas vezes, as atividades realizadas no "tempo livre" servem também para reforçar habilidades ou conhecimentos necessários à atividade profissional".
}

Neste sentido, o que acontece é paradoxal: para se usufruir o lazer, é necessário dispor de tempo, que é subtraído ao tempo de trabalho, mas, contraditoriamente, o consumo do lazer exige mais renda, o que implica mais tempo dedicado ao trabalho, para obter mais dinheiro. 


\section{CONSIDERAÇÕES FINAIS}

O turismo em Caldas Novas é motivado pela existência da instância hidromineral. Cerca de $76 \%$ dos turistas que visitam a cidade atribuem a sua visitação a existência de águas termais, porém deste percentual, cerca de $40 \%$ expressam que suas expectativas em relação ao lazer poderiam ter sido superadas, caso houvesse o incremento de outros roteiros turísticos na cidade, isto é, uma maior diversificação de atividades de lazer, o que contribui para demonstrar a importância da inserção de um roteiro turístico alternativo em Caldas Novas. Desta forma, é importante implantar mais opções de lazer que atendam as exigências dos mesmos, ou seja, é preciso criar e/ou redimensionar outros espaços e equipamentos de lazer da cidade.

Por meio da pesquisa procurou-se saber também como os turistas classificam o lazer em Caldas Novas. Trinta e sete por cento acharam excelente o lazer oferecido pela cidade, 33\% classificaram como bom e 30\% acreditam que o lazer na cidade precisa melhorar muito, esses percentuais indicam que o lazer em Caldas Novas precisa ser redimensionado, pois a quantidade de turistas insatisfeitos ou que acreditam que o lazer na cidade poderia ser melhor é significativa, representando $1 / 3$ do universo pesquisado. Tendo em vista que o turista de hoje é exigente em relação à obtenção de informações e por conhecer outros atrativos turísticos, resolveu-se perguntar à população alvo do estudo o que ela achava que precisava ser melhorado no lazer. Para esta pergunta obteve-se como resposta que: 20\% acham que a recreação dentro dos clubes precisa ser melhorada, 17\% já querem que os preços dentro dos clubes sejam mais acessíveis, mas a grande maioria acredita que precisa ter mais atrativo.

Por isso é importante que exista um itinerário alternativo, tendo como opções à visitação ao Lago de Corumbá e ao Parque da Serra de Caldas, onde os turistas encontrarão além de muita beleza natural, a pratica do turismo náutico e do ecoturismo - caminhadas ecológicas que propiciam 
contato direto com a flora e a fauna do cerrado goiano, podendo ainda vislumbrar o incremento do Turismo Sustentável.

Os objetivos foram alcançados, na medida em que foi possível analisar as opções de lazer em Caldas Novas. Viabilizando uma alternativa de lazer que "foge" dos roteiros tradicionais e que represente o Turismo Sustentável. Por isso pode-se dizer que foi possível criar outra opção de lazer, aliado ao conceito de sustentabilidade. Tendo em vista que os turistas passaram a ter mais conhecimento sobre o Lago de Corumbá e o sobre o Parque Estadual da Serra de Caldas Novas, sendo que este era um dos principais objetivos deste trabalho.

Neste âmbito, verificou-se que para a implantação e implementação de um projeto de turismo sustentável em Caldas Novas é imprescindível contar com a participação da população local no planejamento da atividade turística, pois o impacto dessa atividade pode ir muito além da degradação ambiental e cultural; suas conseqüências poderão alcançar negativamente culturas e relações sócias, criando conflitos e inviabilizando o fomento das áreas atingidas pelo seu crescimento.

Para concluir o trabalho, não pode - se deixar de ressaltar a importância do lazer diversificado para o incremento da atividade econômica da cidade de Caldas Novas. E também a importância de novos estudos sobre o tema, haja vista que o turismo é uma ferramenta efetiva para o desenvolvimento sustentável local. Talvez, a única coisa que falta agora seja pensar na atividade turística de modo sistêmico, integrador e integral e fazer com que a chamada "indústria do turismo" tenha seus parâmetros redefinidos para o desenvolvimento local da cidade de Caldas Novas. Com isso, defendese que o turismo não será possível se a população local não acredite e contribua para que ele seja uma atividade sustentável, isto é, o tipo de desenvolvimento que considera como importante para a qualidade de vida da população local, desta geração e de futuras. 


\title{
REFERÊNCIAS BIBLIOGRÁFICAS
}

\author{
AlBuQuerque, Carlos. Caldas Novas - Além das Águas Quentes. \\ Caldas Novas: Kelps, 1996. \\ BACAL, Sarah. Lazer e o universo dos possíveis. São Paulo: Aleph, 2003. \\ BRUHNS, Heloísa Turini e GUTIERREZ Gustavo Luis. O corpo e o Lúdico. \\ Campinas, SP: Autores Associados, 2000. \\ CAMARGO, Luiz Octavio de Lima. O que é Lazer? São Paulo: Brasiliense, \\ 2003.
}

DUMAZEDIER, Joffre. Planejamento de lazer no Brasil: a teoria sociológica de decisão. São Paulo, SP: SESC, 1980. . Sociologia empírica do lazer. São Paulo: Perspectiva, 1999.

KRIPPENDORF, Jost. Sociologia do turismo: para uma nova compreensão do lazer e das viagens. São Paulo: Aleph, 2001.

LUCHIARI, Maria Tereza. "Turismo, natureza e cultura caiçara: um novo colonialismo". In. SERRANO, Célia e BRUHNS, Heloisa. Viagens à natureza: turismo, cultura e ambiente. Campinas: Papirus, 1997.

MARCELINO, Nelson Carvalho. Lazer e Humanização. Campinas, SP: Papirus, 1983.

NEGRINE, Airton. Recreação na hotelaria: o pensar e o fazer lúdico. Caxias do Sul, RS: Educs, 2001.

PELLEGRINI FILHO, Américo. Ecologia, cultura e turismo. Campinas: Papirus, 1997.

RIBEIRO, Gustavo e BARROS, Flávia. "A corrida por paisagens autênticas: turismo, meio ambiente e subjetividade no mundo contemporâneo". In. SERRANO, Célia e BRUHNS, Heloisa. Viagens à natureza: turismo, cultura e ambiente. Campinas: Papirus, 1997.

SACHS, Ignacy. "Estratégias de transição para o século XXI. In. BURSZTYN, M. Para pensar o desenvolvimento sustentável. São Paulo: Brasiliense, 1993. 
SERRANO, Célia e BRUHNS, Heloisa. Viagens à natureza: turismo, cultura e ambiente. Campinas: Papirus, 1997.

SESC/WLRA, Lazer numa sociedade globalizada: São Paulo, 2000.

SUASSUNA, Dulce Maria Filgueira de Almeida. "Uma pergunta que se faz ao recém-chegado: quem és? O Projeto Tamar e sua intervenção em comunidades pesqueiras. Tese de doutorado apresentada ao Programa de Pós-Graduação em Sociologia da Universidade de Brasília, maio de 2001. SWARBROOKE, John. Turismo Sustentável: setor publico e cenários geográficos, vol. 3. São Paulo: Aleph, 2000.

TRIGO, Luiz Gonzaga Godoi. A Sociedade pós-industrial e o profissional em Turismo. Campinas, SP: Papirus, 1998.

WAICHMAN, Pablo. Tempo livre e Recreação. Campinas, SP: Papirus, 1997.

Documentário

Masagão, Marcelo. Nós que aqui estamos por vós esperamos, Brasil, 1999. 


\section{ANEXO I - QUESTIONÁRIO}

O questionário foi realizado na Secretaria de Turismo e Cultura de Caldas Novas, e tem por objetivo identificar o nível de satisfação dos turistas em relação aos atrativos turísticos da cidade. O período de aplicação do questionário será em janeiro de 2005.

Instruções: os questionários foram feitos com perguntas abertas e fechadas, onde os turistas poderão colocar suas criticas, sugestões e/ou reclamações.

Por meio desse questionário que conta com onze perguntas foi possível medir o grau de satisfação e/ou insatisfação dos turistas em relação a Caldas Nova e ao lazer que a cidade oferece.

A seguir o questionário que foi aplicado aos turistas:

1 - Como você tomou conhecimento sobre Caldas Novas?

2 - O que motivou sua visita a Caldas Novas?

3 - Como você organizou sua viagem para Caldas Novas?

4 - Antes de chegar à cidade qual era a sua expectativa quanto a oferta de atrativos turísticos?

5 - Ao chegar a Caldas Novas qual foi a sua expectativa quanto a oferta de atrativos turísticos da cidade?

6 - Em geral, como você classifica o lazer em nossa cidade?

7 - O que você acha que precisa ser mudado em relação ao lazer de Caldas Novas?

8 - Durante a estada em nossa cidade, qual o atrativo turístico que você mais gostou?

9 - È a primeira vez que visita Caldas Novas?

10 - Pensa em voltar outras vezes?

11 - Você conhece o Lago de Corumbá e/ou a Serra de Caldas? 